\title{
Artrogripose em caprino: Relato de caso
}

\author{
[Arthrogryposis in a goat: a case report] \\ V. Schmidt ${ }^{1}$, R.T. de Oliveira ${ }^{2}$ \\ ${ }^{1}$ Departamento de Medicina Veterinária Preventiva - UFRGS \\ Av. Bento Gonçalves, 9090 \\ 91540-000 - Porto Alegre, RS \\ ${ }^{2}$ Departamento de Patologia Clínica Cirúrgica - UFRGS
}

\section{RESUMO}

Relata-se a ocorrência de artrogripose congênita em um caprino fêmea da raça Anglo-Nubiana, no município de Viamão, RS, provavelmente induzida por hipertemia ocorrida durante a gestação.

Palavras-chave: artrogripose, caprino

\section{ABSTRACT}

This is a report of a case of arthrogryposis in an Anglo-Nubian female kid in Rio Grande do Sul, Brazil. This pathology was probably induced by an episode of hyperthermia during gestation.

Keywords: arthrogryposis, goat

\section{INTRODUÇÃO}

A artrogripose foi descrita pela primeira vez na Nova Zelândia em 1956-57, sendo definida como uma contratura permanente das articulações presente ao nascimento, podendo ocorrer tanto no homem como nos animais. Entretanto, os órgãos internos, o sistema nervoso central e o tecido muscular, historicamente, apresentam-se normais (Greene et al., 1973).

O distúrbio locomotor tem sido associada à ingestão de Lupinus caudatus, L. sericeus (Greene et al., 1973) e Nicotiana tabacum (Crowe e Pike, 1973), à infecções virais, ao aumento de temperatura corporal durante a prenhez (Greene et al., 1973) e à alterações genéticas (Nes et al., 1982; Lomo, 1985).
Recebido para publicação em 25 de junho de 2003

Recebido para publicação, após modificações, em 4 de fevereiro de 2004

E-mail: veronica.schmidt@ufrgs.br
A artrogripose é uma síndrome que envolve mais de uma entidade patológica e etiológica. Em caprinos, foi registrada a ocorrência de artrogripose no Japão (Kurogi et al., 1977) e na ilha de Chipre (Sellers e Hernimann, 1981), associada à presença do vírus Akabane. Nos Estados Unidos, a ocorrência de artrogripose está associada à ingestão de plantas com alcalóides (Panter et al., 1990). No Brasil, Borges et al. (1997) relataram sua ocorrência em bovino e ovino sem, no entanto, estabelecerem a etiologia.

O objetivo do trabalho é relatar a ocorrência de um caso de artrogripose congênita em um caprino fềmea da raça Anglo-Nubiana. 


\section{CASUÍSTICA}

Em um capril, no município de Viamão, RS, um recém-nascido, fêmea da raça Anglo-Nubiana, com impossibilidade de manter-se em estação após o nascimento, permaneceu em decúbito lateral e foi alimentado artificialmente com leite materno por 10 dias até a morte.

Nos últimos 10 anos constavam dos registros sanitários da criação medidas de profilaxia como: isolamento dos caprinos descendentes de matrizes provenientes de cabril com diagnóstico positivo de micoplasmose caprina e programa de controle da artrite encefalite viral caprina, mediante abate de animais com diagnóstico sorológico e/ou sintomatologia compatível. Verificou-se, ainda, registro de um surto compatível com ectima contagioso, a partir do qual foi estabelecido um programa de vacinação em fêmeas prenhes e filhotes, ocorrência de linfadenite caseosa e descrição clínica de fêmeas que apresentavam apatia e elevação de temperatura corporal durante a gestação, sem registro de diagnóstico provável.

À necropsia evidenciaram-se ao exame externo bom estado nutricional, mucosas pálidocianóticas e flexão da articulação carpo-radial com contratura muscular. O quadro, sugestivo de artrogripose, mostrou contratura simétrica e bilateral das articulações. Ao exame histológico verificou-se que não houve lesão consistente nos tecidos. O exame interno revelou congestão e edema pulmonar, dilatação cardíaca e congestão visceral. O encéfalo apresentou edema e discreta congestão.

Para o exame microscópico, secções de pulmões, fígado, rins, encéfalo e medula, coletados e fixados em formalina a $10 \%$, embebidos em parafina e secionados com $6 \mu$ de espessura, foram corados com hematoxilina e eosina. Foram confirmados edema e congestão da medula e do encéfalo.

Considerando o histórico clínico, foi dado o diagnóstico de artrogripose.

\section{DISCUSSÃO}

A artrogripose é um distúrbio locomotor associado a diversos fatores etiológicos. Casos de artrogripose têm sido relacionados à alterações genéticas (Lomo, 1985), ingestão de plantas tóxicas, infecções virais e aumento da temperatura corporal durante a prenhez (Greene et al., 1973).

Diferentemente do relatado nas espécies eqüina (Nes et al., 1982) e bovina (van Huffel e Moore, 1985), em que há predominância de machos afetados, este caso ocorreu em uma fêmea.

Os casos de artrogripose de origem genética, descritos em suínos (Lomo, 1985), eqüinos (Nes et al., 1982) e bovinos (Russel et al., 1985) ocorreram em animais com ascendência comum. Nestes casos, espera-se número expressivo de animais doentes no rebanho.

O exercício limitado da fêmea durante a gestação poderia levar à rigidez muscular do feto, resultando em artrogripose (van Huffel e Moore, 1985). Entretanto, no rebanho em estudo, as fêmeas caminhavam muito em busca de alimento, por estarem em regime semi-extensivo de criação.

Plantas associadas a relatos de artrogripose em bovinos e suínos, como as dos gêneros Nicotiana e Conium (Forsyth et al., 1996), Prunus e Datura (Poisonous..., 2003) e Lupinus (Abbot et al., 1986), vulgarmente conhecidas como fumo (Nicotiana), cicuta (Conium), pessegueiro bravo (Prunus), trombeteira ou saia branca (Datura) e tremoço (Lupinus) (Hoehne, 1939) não são comuns na região e não foram encontradas na propriedade em estudo. A relação entre essa patologia em caprinos e a ingestão de certas plantas não está clara. Em estudo experimental, quando ocorreu ingestão de Nicotiana ou Conium pela mãe, a limitação dos movimentos dos membros dos recém-nascidos foi restabelecida até 10 semanas após o parto e a ingestão de Lupinus não induziu à artrogripose (Panter et al., 1990).

No presente caso, considerando o histórico sanitário da propriedade, não foi possível relacionar a presença da patologia com enfermidades transmissíveis porque no cabril verificou-se a ocorrência de doenças transmissíveis não relacionadas à patologia, e só ocorreu um caso. A temperatura corporal pode variar de acordo com a hora do dia, o exercício físico, a exposição prolongada ao sol, dentre 
outros fatores. Para uma fêmea em descanso à sombra considera-se normal a temperatura corporal de 39,1 a 39,4 $4^{\circ} \mathrm{C}$ (Mackenzie, 1980). Agraz (1981) considera $40^{\circ} \mathrm{C}$ como a temperatura corporal média de uma fêmea caprina, sendo o limite máximo de $40,2^{\circ} \mathrm{C}$ para a raça AngloNubiana.

Hipertermia é definida como a elevação da temperatura corporal em pelo menos $1,5^{\circ} \mathrm{C}$ (Martinéz-Frias et al., 2001). Na ficha de controle da mãe estavam anotadas três tomadas de temperaturas de até $41,5^{\circ} \mathrm{C}$ no terço inicial da gestação, caracterizando um quadro de hipertermia, considerado fator determinante de artrogripose em recém-nascido (Martinez-Frias et al., 2001).

A artrogripose não tem sido relatada em caprinos e sua ocorrência tem sido relacionada à arboviroses (Commitee..., 1998). A ocorrência já foi relacionada com as doenças de Akabane (Kurogi et al., 1977), de Wesselsbron (Armed..., 2003), Cache Valley, febre do Vale Rift (Commitee..., 1998) e pestivirus (Tempesta, 2002), ainda não descritas no Brasil. A doença língua azul, que também pode cursar com artrogripose (Commitee..., 1998), foi registrada no Estado do Paraná (Office..., s.d.).

\section{REFERÊNCIAS BIBLIOGRÁFICAS}

ABBOTT, L.C.; FINNEL, R.H.; CHERNOFF, G.F. et al. Crooked calf disease: a histological and histochemical examination of eigth affected calves. Vet. Pathol., v.23, p.734- 740, 1986.

AGRAZ, G.A.A. Caprinotecnia. México: Universidad de Guadalajara, 1981. v.1.84p.

ARMED Forces Institute of Pathology. Disponível em: <http://www.afip.org/vetpathp $>$. Acessado em: $16 / 06 / 2003$.

BORGES, A.S.; MENDES, L.C.N.; VASCONCELOS, R. et al. Myelodysplasia and spina bifida in ruminants: a case report. Arq. Bras. Med. Vet. Zootec., v.49, p.685 - 692, 1997.

COMMITEE on foreign animal diseases of United States Animal Health Association. Richmond, Virginia: USAHA, 1998. 432p.

CROWE, M.; PIKE, H.T. Congenital arthrogryosis associated with ingestion of tobacco stalks by pregnant sows. J. Am. Vet. Med. Assoc., v.162, p.453 - 455, 1973.

FORSYTH, C.S.; SPETH, R.C.; WECKER, L. et al. Comparision of nicotinic receptor binding and biotransformation of coniine in the rat and chick. Toxicol. Lett., v.89, p.175 - 193, 1996.

GREENE, H.J.; LEIPOLD, H.W.; HUSTON, K. et al. Bovine congenital defects: Arthrogryposis and associated defects in calves. Am. J. Vet. Res., v.34, p.887 - 891, 1973.

KUROGI, H.; INABA, Y.; TAKAHASHI, E. et al. Experimental infection of pregnant goats with Akabane virus. Natl. Inst. Anim. Health Q., v.17, p.19, 1977.

LOMO, O.M. Arthrogryposis and associated defects in pigs: indication of simple recessive inheritance. Acta Vet. Scand., v.26, p.419 - 422, 1985.

MACKENZIE, D. Goat husbandry. 4.ed. London: Faber \& Faber, 1980. 375p.

MARTINEZ-FRIAS, M.L.; MAZARIO, M.J.G.; CALDAS, C.F. et al. High maternal fever during gestation and severe congenital limb disruptions. Am. J. Med. Genet., v.98, p.201 - 203, 2001.

NES, N.; LOMO, O.M.; BJERKAS, I. Hereditary lethal arthrogryposis ("muscle contracture") in horses. Nord. Veter. Med., v. 34, p. 425 - 430, 1982.

OFFICE International of Epizooties Disponível em: $<$ http://www.oie.int/>. Acessado em: 16/06/2003.

PANTER, K.E.; BUNCH, T.D.; KEELER, R.F. et al. Multiple congenital contractures (MCC) and cleft palate induced in goats by ingestion of piperidine alkaloid-containing plants: reduction in fetal movement as the problable cause. J. Toxicol. Clin. Toxicol., v.28, p. 69-83, 1990.

POISONOUS plants information database. Disponível em: <http://www.ansci.cornell.edu/plants $>$. Acessado em: 16/06/2003.

RUSSEL, R.G.; DOIGE, C.E.; OTERUELO, F.T. et al. Variability in limb malformation and possible significance in the cattle (Syndrome of arthrogryposis and palatoschisis). Vet. Pathol., v.22, p.2 -12, 1985.

SELLERS, R.F.; HERNIMANN, K.A Neutralising antibodies to akabane virus in ruminants in Cyprus. Trop. Anim. Health Prod., v.13, p.57-60, 1981.

TEMPESTA, M. (Ed.). Recent advances in goat diseases. Ithaca, NY: IVIS, 2002.

Van HUFFEL, X.; MOORE, A. Reflections on the rale of mechanical influences on foetal movement, and the relationship to arthrogryposis multiplex congenita in calves. Vloams Diergeneesk. Ttiijd., v.54, p.470 481, 1985. 